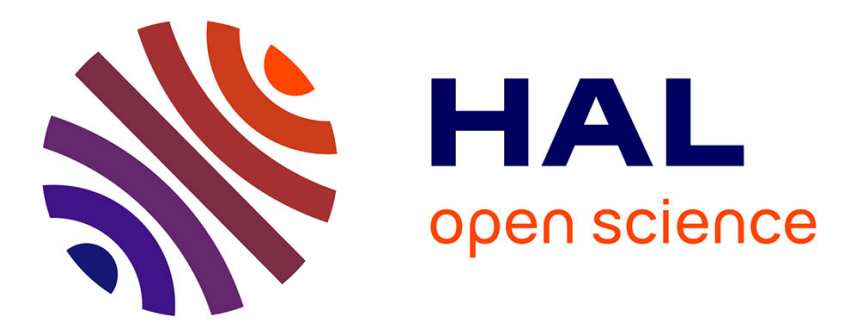

\title{
Exploring the inquiry-based learning structure to promote scientific culture in the classrooms of higher education sciences
}

P S 1 Mello, C C Natale, S L F Trivelato, Patricia Marzin-Janvier, L Q Vieira, Daniel Manzoni de Almeida

\section{To cite this version:}

P S 1 Mello, C C Natale, S L F Trivelato, Patricia Marzin-Janvier, L Q Vieira, et al.. Exploring the inquiry-based learning structure to promote scientific culture in the classrooms of higher education sciences. Biochemistry and Molecular Biology Education, 2019, 47 (6), pp.672-680. hal-02272938

\section{HAL Id: hal-02272938 \\ https://hal.science/hal-02272938}

Submitted on 29 Aug 2019

HAL is a multi-disciplinary open access archive for the deposit and dissemination of scientific research documents, whether they are published or not. The documents may come from teaching and research institutions in France or abroad, or from public or private research centers.
L'archive ouverte pluridisciplinaire HAL, est destinée au dépôt et à la diffusion de documents scientifiques de niveau recherche, publiés ou non, émanant des établissements d'enseignement et de recherche français ou étrangers, des laboratoires publics ou privés. 


\title{
EXPLORING THE INQUIRY-BASED LEARNING STRUCTURE TO PROMOTE SCIENTIFIC CULTURE IN THE CLASSROOMS OF HIGHER EDUCATION SCIENCES
}

\author{
Mello, P. S. ${ }^{1}$, Natale, C. C. ${ }^{1}$, Trivelato, S. L. F. ${ }^{2}$, Marzin-Janvier, P. ${ }^{3}$, Vieira, L. Q. ${ }^{1}$ and \\ Manzoni-de-Almeida, $\mathrm{D}^{4}{ }^{*}$ \\ 1. Departamento de Bioquímica e Imunologia, ICB, UFMG, Belo Horizonte, MG, Brazil \\ 2. Grupo de Estudos e Pesquisa em Ensino de Biologia (GEPEB), Faculdade de \\ Educação da Universidade de São Paulo, São Paulo, Brazil \\ 3. Université de Bretagne Occidentale, Centre de Recherche sur l'Enseignement, les \\ Apprentissages et la didactique (CREAD), Brest, France. \\ 4. Grupo de Estudos e Pesquisa em Ensino \& Ciências (GEPEC), Escola de Ciências \\ Biológicas e da Saúde, Centro Universitário das Faculdades Metropolitanas Unidas, \\ FMU, São Paulo, Brazil \\ * danielmanzoni@gmail.com
}

\begin{abstract}
This paper examines student engagement in an inquiry-based learning activity, planned to provide students with elements in the social, epistemic and conceptual dimensions related to the scientific practice in Immunology. The activity was applied to 39 groups of students enrolled in Immunology or Biochemistry courses in a public university in Brazil. Students performed data-collection through the execution of an in vitro assay. We analyzed how students represent data and use them to support their claims in their written constructs. To clarify which are the productive epistemologies in students' reports we developed a framework for epistemic practice analysis. Our findings point to a pattern of several epistemic practice categories in their written text, mostly related to the particular contingences of data analysis, rather than to theoretical concepts. In addition, we observed that students performed literary inscriptions to represent their data, however, they tended not to cite all data obtained in their written texts. These results suggest that Immunology education strategies should provide students with approaches that explore the role of data representation in the scientific text rhetoric.
\end{abstract}

KEY WORDS: Science higher education; Immunology; epistemic practices

\section{INTRODUCTION}

At the higher education level, conceptions of inquiry-based learning are appealing, since they provide opportunities for students engaged in academic and professional training to establish close contact with typical elements of the scientific communities [1].

The term "inquiry learning" has been defined in many forms and applied to many procedures throughout history [2]. The definition most closely related to this work is that inquiry-based learning is an educational strategy that engages students in science matters [3] by having them perform tasks similar to those scientists perform routinely [4]. Several researchers consider the inquiry learning strategy more effective than traditional instruction [5-7], and other researchers associate inquiry-based learning with the promotion of skills related to processual, procedural, and conceptual scientific knowledge [8].

Teaching science in higher education should contemplate specific features in order to reach the main educational goal: acquiring professional scientific skills. Thus, science 
education must train future professionals to apply their scientific knowledge to their everyday practices in order to benefit society. Therefore, research must be used as precondition for teaching future professionals from biomedical courses [9]. After all, the professional activity that does not use scientific knowledge reverts to the simple reproduction of procedures for which academic formation is not necessary. Thus, using research as a methodological resource for teaching at universities is appealing, because it offers opportunities for students to use elements of the scientific practice to develop comprehension of science in the three dimensions of knowledge [10].

It is crucial for students to learn how to observe what counts as valid knowledge for the specific community in which they are inserted [1]. Latour and Woolgar (1986, p. 60) name "literary inscription" all forms of data representation (points, codes, charts, maps, spectra, photos) that support claims when they are tied to the assertions in scientific texts. There is a different epistemic value for each literary inscription [11], and then each knowledge community utilizes the literary inscriptions related to the specific knowledge under study, as a resource for agonistic debates. A professional in science-related fields should be proficient in representing and interpreting data, however, recognizing evidence in the results is not a trivial matter.

Epistemic practices are good resources for authors to analyze the productive epistemologies in student's discourses. Epistemic practices appear whenever the social practices for knowledge establish a routine pattern [10], allowing researchers to list and classify the sources used by the community upon which knowledge is built. Epistemic practices are social, cognitive and discursive activities given to a community that shares common values, meanings and tools [12]. As a result, they are interactional, contextual, intertextual, consequential [10], and contribute to shape the cognitive processes that lead to knowledge. The most recent framework for epistemic practices analysis sets them into four categories based on normative and educational goals: proposition, communication, evaluation and legitimation of knowledge. Because they vary according to the systematic ways that each community functions, the types of epistemic practices situated in each category will also vary for each area of knowledge [10].

Immunology deals with themes of relevance for human health. However, there is a lack of studies on teaching and learning Immunology. Our group has been analyzing the written discourse produced by students while solving an Immunology problem $[13,14]$. After receiving active-based learning instruction in Toulmin's argument layout [15], students deal with data previously obtained to make claims and justify them according to scientific conceptions. Our data suggest that students use categories of epistemic practices related to production of knowledge in their arguments [13]. These epistemic practices are similar to those performed by scientists while analyzing data, suggesting that the activity favored use of skills related to science [14]. Here, we seek to describe patterns related to data representation and use of evidence in the students' written text to clarify features that could be referenced in future projects aimed at teaching and learning Immunology.

We consider that exposing students to complex tasks is an important way to bring them closer to key elements of the scientific practice in Immunology. Our goal is to analyze student's written constructs to answer three research questions: 1) What kind of literary inscriptions are performed by students to represent raw experimental data? 2) Do students use literary inscriptions in their written texts? 3) What are the categories of epistemic practices utilized by the students to explain their claims?

\section{METHODOLOGY}




\section{Inquiry-based activity and its application to undergraduate classes}

In this work, we describe and interpret interactional phenomena emerging in situ [1]. Thus, our methodological approach is drawn from qualitative research [16].

A detailed description of the inquiry-based activity is described in Mello et al. [17]. Due to the importance of the experimental activity in building knowledge in Immunology, we created an activity based on experimental procedures to collect data. Cells of the immune system express surface-receptors or secret immunomodulators, which bind to other molecules. Based on this principle and on the possibility of performing an assay that would be feasible within the available time and met ethical and financial limitations, we elected the "analysis of complement fixation" as our experimental approach.

We asked students to choose their own test substances or physical conditions that putatively would interfere with the complement cascade. By using this strategy, we expected to stimulate the curiosity of the students and to encourage them to apply the formal disciplinary theoretical knowledge or informal daily observations. Since they were free to choose any substance related to their personal and academic routines, we expected a link between everyday life and science.

According to the educational goals and because of time limitation, we adopted a model of "structured inquiry" [6]. An inquiry-learning approach is classified as such when the teacher proposes a general problem to the students. The problem posed was: "Are there substances (or physical conditions) that interfere with the complement cascade?". In our model, we moved beyond the basic layout of a structured inquiry by proposing that students create their own experimental question, which should necessarily associate the substance chosen by them with the problem posed by the teacher. Moreover, we also provided students with the method for data collection, but the data interpretation was a task they should perform by themselves.

During the experimental class, students found on their workbench all the labelled reagents, necessary equipment and a standardized experimental protocol according to Morgan (2000, p.63). Briefly, the protocol instructed them to first pipette different concentrations of the substance with a fixed volume of mouse serum aiming to build a curve, and incubate the tubes in physiological conditions of $\mathrm{pH}$, temperature and osmolarity. Then, they should transfer an amount of that solution to a microplate containing rabbit erythrocytes in a concentration previously determined. They also had extra samples as "control groups": mouse serum with erythrocytes; substance with erythrocytes; water with erythrocytes (" $100 \%$ lysis") and saline solution with erythrocytes (spontaneous background lysis). After incubation, students should centrifuge the microplate to concentrate whole erythrocytes in the the bottom of the plates. They also took a picture of the plate to have a qualitative interpretation of the results. After that, they gently transferred a volume of the supernatant to another plate, to perform absorbance measurements. Using the numeric values obtained, they must calculate the percentage lysis in each condition. We planned the template for a written report, called "Lab notebook" [14] to favor the assembly of assertions leading to scientific arguments. Thus, we prepared a set of commands that students should fill with the experimental question, hypothesis, expected results, motivation for choosing the test conditions, and the concentration of the substance solution or specifics of the test conditions. In addition, after performing the lab tasks, they should get back to the "Lab notebooks" and fill other commands such as the description of methodology, their data representation, description of results, discussion and conclusion. 
We devised two protocols with different levels of complexity. In both protocols, teacher and students interacted in a first moment to establish conceptual knowledge (conceptual goal) of the complement system, but only one protocol included an extra step (Table SI, activity 3) planned to improve the achievement on the goals: we provided students with seminal scientific papers on the complement system, which they should read and present the strategies used by the authors to convince the reader of the interpretation of the results.

To guide students through the reading task, we provided them with a set of contents that we expected to see in the presentation:

1) "After reading the paper, select a figure that you think it is very import to the work";

2) "Present the information that can be extracted from the figure";

3) "Clarify the previous knowledge the authors already had, as well as the purpose of the experiment performed by them";

4) "Discuss the manners by which the authors tied their own evidences with the knowledge generated by others.

Both protocols of the inquiry-based sequence are presented in Table SI.

Groups of students engaged in Immunology and Biochemistry classes in a public university in Brazil performed the two models of inquiry. Of the 39 groups, 15 did not perform activity 3 described in Table SI, and 24 performed all the activities in Table SI. To favor our descriptions, we named each of the protocols as A (the one in which activity 3 is absent) and B (the one in which activity 3 was performed). To avoid the identification of the participants we codded all the 39 "Lab notebooks" with the letter G followed by a number, from G1 to G39. We previously submitted this study to the local ethics committee, which reviewed and approved our protocol (CAAE 58960416.6.0000.5149 / protocol number: 1.717.179). Participants signed an informed consent allowing the analysis and publication of the information collected in classes. For all the activities in both protocols, students received some degree of instruction by the teacher, who avoided providing them with ready answers, but asked questions to direct them to reasoning, as showed in Table SII.

\section{Data analysis}

Our framework for epistemic practices analysis was built according to Manzoni-deAlmeida et al. (2016), and Kelly and Licona (2018), to contain epistemic practices categories related to the ones found in scientific texts describing experimental results.

We went through students' written constructs looking for the epistemic practices. We divided each text into sentences, which were considered our unit of analysis. The end of the sentence is marked by a period (.) or a colon (:). The sentences were analyzed according to our framework shown in Table SIII.

\section{RESULTS} activity

Engagement of students while performing the protocol A of the inquiry-based 
During the planning phase, students engaged in protocol A chose test conditions, e.g.. acetic acid, albumin, vodka, dipyrone, chalk dust, glucose, saliva, fermented milk, dry baking yeast. Only one group chose to test variations of a physical condition: temperature.

We considered as valid the experimental questions in which we found some speculation about the effects caused by the test substance on hemolysis mediated by complement. As showed in figure 1A, eight out of 15 groups formulated valid experimental questions. For example, group 11 asked "Can dipyrone bind to the complement system?".

As to the analysis of hypothesis and expected results, we found that some groups registered the hypothesis under the command originally planned for expected results registration. This fact suggests that the distinction between these elements was not consolidated in the pre-experimental phase. The framework of epistemic practice categories allowed us to localize the sentence corresponding to hypothesis even when students registered them in a command other than the one intended by us. The analysis of the students' writings showed that 12 out of 15 groups formulated valid hypothesis (Figure 1B), and six groups formulated valid expected results (Figure 1C).

From the inquiry phase III (Table SI), students should deal with raw data obtained to produce their assertions. According to Latour (1987), the production of non-verbal inscriptions and the use of the evidences extracted by them in the written text is a strategy to transmit reliability to claims.

We then decided to check out how students represented their data in the "Lab notebooks". Eleven out of 15 groups represented their data using non-verbal inscriptions (Figure 2A), such as images, tables and calculations (Figure 2B). The prevalence of calculations in detriment of other forms of representation is not surprising, since the protocol contained guidance on how to calculate the percent lysis using the absorbance values. No groups used charts to represent data (Figure 2B).

Kelly and Duschl (2002) point out that the social practices of science provide information on how communities shape knowledge in their specific contexts. Thus, categorization of epistemic practices in students' written material reflects resources used by them to formulate and support their assertions. Thus, we performed the analysis of epistemic practices in each sentence of the five last commands in the "Lab notebooks". Figure 3 shows the occurrence of different categories of epistemic practices in the students' constructs. The analysis suggests that the activity favored the appearance of all the categories from our framework, distributed in texts averaging 10 sentences, with the predominance of the categories developing hypothesis, making literary inscriptions, explaining the scheme of investigation. We relate the high appearance of this last category to one of the commands of "Lab notebooks", which asked students to describe the methods used in the experiment.

We observed a low number of groups performing the categories related to theoretical knowledge (conceptualize and relating data and theory), compared to the number of groups performing the categories related to the specific data analysis (describing data, comparing data, interpreting data, explaining data). We had expected this occurrence, since the inquirybased activity demanded the analysis of experimental data. However, we expected to see a higher number of groups performing categories related to the data analysis (describing data, comparing data, interpreting data, explaining data). It is possible that the low number of each of the data analysis categories is simply due to the choice of strategy to analyze data: describing data in detriment of comparing data, for example.

From Figures 2A and 3, it is possible to note that 11 groups made literary inscriptions to represent raw data, but only half of the groups mentioned the inscriptions explicitly in their texts. To investigate how students use evidences obtained from their analysis, we looked up the sentences in which their claims were clearly supported by data, and then we graded the 
written texts as "always", "partially" and "never". Groups classified as "always" built all of their constructs upon data information, and groups classified as "partially" made at least one assertion based on personal beliefs or on observations from data not attached to the "Lab notebook". Groups classified as "never" did not support any of their claims with evidences.

Because we noticed that some groups performed more than one type of literary inscription, we checked how many of the inscriptions were used to formulate their assertions. Then, we graded the texts as "all", "partial use", or "none", depending on how many inscriptions made by them were used to making the verbal constructs. Some groups produced claims not supported by data, as seen in Figure 4A. These groups are the ones which did not perform literary inscriptions, in addition to the ones that described information not attached to the reports. For example: many groups performed calculations, but described features related to the macroscopic observations (e.g. pellet presence/absence, or solution color and turbity). However, they did not attach the image to the "Lab notebooks". Interestingly, none of the groups used all the literary inscriptions in the text (Figure 4B). These data suggest that the groups failed to develop the comprehension of data representation as a resource of rhetoric, but used literary inscriptions as an instructional and illustrative component.

To illustrate our analysis, we present in Table SIV an excerpt extracted from G14's "Lab notebook". They tested the possibility that chalk dust interfered in hemolysis mediated by the complement system, to associate a putative interaction with the complement system to allergic reaction to chalk dust. The analysis of epistemic practices shows that they appealed to several descriptions and comparisons to relate the evidences obtained from the "experimental groups" and "control groups" in both literary inscriptions: calculation and plate design. They then used all those evidences to claim that chalk dust does not bind to the complement components but promotes hemolysis by itself (sentence 19).

\section{The engagement of students while subjected to Protocol B of the inquiry-based activity}

Students who performed this form of inquiry engaged in scientific paper presentations primarily (inquiry-phase I: activity 3 - table SI). We planned this extra step to provide them with the comprehension of how immunologists build models based on their own data and communicate knowledge. We also wanted to provide them with concept and data source to favor construction of a structured scientific text.

These students chose aspirin, glucose, Ibuprofen, sheep blood (courtesy of the Veterinary School, UFMG), Peumus boldus' extract, Biomphalaria hemolymph (courtesy of the Parasitology Department, UFMG, and obtained from healthy snails), saliva, skim milk and honey.

All 24 groups that formulated valid experimental questions (Figure 5A) and hypothesis (Figure 5B). Only four groups did not formulate expected results in the preexperimental phase (Figure 5C). These results suggest that the guided presentation of scientific papers contributed to their comprehension of these three scientific practices.

Analysis of data representation shows that 22 out of 24 groups performed literary inscriptions (Figure 6A), and most of the non-verbal inscriptions were also identified by legends. In addition, we observed that students incremented their data representations by 
performing more than one literary inscription in "Lab notebooks". There was a prevalence of images, calculation and tables, as well as charts (Figure 6B).

Figure 7 shows the profile of epistemic practice prevalence in the students' written constructs. The analysis suggests the activity favored the appearance of all the categories of epistemic practices, with the predominance of making literary inscriptions, asking questions, making hypothesis, and explaining the scheme of investigation. This last category is related to the command that asked for a methodological description, and in this case, we also observed that students usually described elements of the experimental procedure to find explanations for data that did not fit an expected pattern (monitoring anomalous results).

A great number of groups performed comparisons (comparing data) and interpretations (interpreting data). On the other hand, a low number of groups performed the categories related to theoretical knowledge (conceptualize and relating data and theory).

In Figure 8A, we show that 15 out of 24 "Lab notebooks" contained claims based on the obtained data. Groups classified as "never" are the ones who did not attach any kind of data in their "Lab notebooks", and the five groups classified as "partially" sometimes mentioned data descriptions that were not attached to "Lab notebooks". When an author does not use data to support the information under debate, it is impossible to make inferences about the reliability of the information. Thus, texts with this characteristic drift from the concept of a scientific text. Figure $8 \mathrm{~B}$ shows that eight groups used all the literary inscriptions. Most groups, however, registered a great number of literary inscriptions (Figure 6B) but did not use all of them in their written constructs (Figure 8B). Taken together, these data suggest that active learning-based activities that focuses on data usage in scientific texts is needed to improve the achievement of this skill by students.

We found evidences that students developed a line of scientific reasoning while analyzing experimental data. To illustrate this observation, we present an excerpt from G38 in Table SV. This group chose to test sodium hydroxide on the complement system, based on the information that a chemical reaction occurs between sodium hydroxide and the magnesium ion. Their hypothesis was that the product of the reaction would remove magnesium from the medium. Since magnesium is an important co-factor in the complement cascade, its removal would interrupt the chain of reactions.

We categorized about 40 sentences in their "Lab notebook". The categories were: discussion supported by several data sources (sentences 18 and 28), by theoretical knowledge (sentences 19-22) and by selection of evidences (sentences 28 and 29). The epistemic practices categories for this group are presented in Table SV.

\section{DISCUSSION}

This work presents the analysis of a level I [6] inquiry-based learning activity, planned to offer opportunities in the three different dimensions of knowledge [10] related to Immunology. Experimental activity comprises the resource used by immunologists (social dimension) to test the influence of a substance on the complement system cascade (conceptual knowledge) and, by performing this task, understand the basis of the conceptual knowledge (epistemic knowledge).

Our analysis showed that both the inquiry-learning protocols (A and B) promoted engagement in scientific practices, which can be confirmed by the appearance of different categories of epistemic practices related to experimental data analysis in the written constructs (Figures 4 and 8). This work raises important issues related to the role of data representation 
and use of evidences in the students written constructs. Some groups did not used in their discussion all the literary inscriptions that they performed, even the ones who executed the protocol B, with guided reading and presentation of scientific papers (Figure 5 and 9). We think it is possible that students used tables, pictures and charts without realizing the importance of the systematization and representation of data. It seemed that students were using data representation as illustrations rather than realizing that data representation is actually the core of a scientist paper. These observations suggest a need for more activelearning strategies focused on debating the elements of rhetoric and persuasiveness of the scientific text. These results corroborate other observations that claim for more training on these abilities [18].

In addition, it is thought that scientific training must consider core elements used for inquiry in their disciplines of interest [19-21]. The lower number of sentences categorized in the epistemic practices conceptualize and relating data and theory corroborate this conclusion. According to Kelly and Takao (2002), one criterion to estimate the strength of students' arguments based on scientific rhetoric is the ratio of data statements to theory statements. In our analysis, we found more sentences classified in epistemic practices related to data analysis (comparing, interpreting, describing and explaining data), than in epistemic practices related to theory statements, suggesting that students need to be trained in the genre of scientific texts.

\section{FINAL CONSIDERATIONS}

Our strategy to teach immunology by doing science was a complex activity that included: 1) dealing with unknown conditions that entailed technical difficulties, such as pipetting viscous substance, solid particles in suspension, turbidity which affected reading, etc; Students had to, in a short time, solve these difficulties. 2) Results were obtained indirectly, that is, lysis or no lysis had to be interpreted as complement integrity or consumption. These are typical Immunology practices, and the performance of such practices should be encouraged in classrooms so that students are more aware of how textbook knowledge is obtained. We also determined the several categories of epistemic practices that emerged during problem solving. Our findings contribute to the improvement of the knowledge in science education.

\section{REFERENCES}

1. Kelly, G.J. and R.A. Duschl. Toward a research agenda for epistemological studies in science education. in Annual Meeting of the National Association for Research in Science Teaching. 2002. New Orleans.

2. DeBoer, G.E., Historical Perspectives On Inquiry Teaching In Schools, in Scientific Inquiry and Nature of Science: Implications for Teaching, Learning, and Teacher Education, L.B. Flick and N.G. Lederman, Editors. 2006, Springer Netherlands: Dordrecht. p. 17-35.

3. Council, N.R., A Framework for K-12 Science Education: Practices, Crosscutting Concepts, and Core Ideas. 2012, Washington, DC: The National Academies Press. 400.

4. Keselman, A., Supporting inquiry learning by promoting normative understanding of multivariable causality. Journal of Research in Science Teaching, 2003. 40(9): p. 898-921. 
5. Alfieri, L., et al., Does discovery-based instruction enhance learning? Journal of Educational Psychology, 2011. 103(1): p. 1-18.

6. Blanchard, M.R., et al., Is Inquiry Possible in Light of Accountability?: A Quantitative Comparison of the Relative Effectiveness of Guided Inquiry and Verification Laboratory Instruction. Science Education, 2010. 94(4): p. 577-616.

7. Furtak, E.M., et al., Experimental and Quasi-Experimental Studies of Inquiry-Based Science Teaching:A Meta-Analysis. Review of Educational Research, 2012. 82(3): p. 300-329.

8. Lee, K., et al., Do Different Levels of Inquiry Lead to Different Learning Outcomes? A comparison between guided and structured inquiry $A U$ - Bunterm, Tassanee. International Journal of Science Education, 2014. 36(12): p. 1937-1959.

9. Lampert, E., $O$ ensino com pesquisa: realidade, desafios e perspectivas na Universidade brasileira. Revista Galego-Portuguesa de Psicoloxía e Educación, 2008. 16: p. 31-44.

10. Kelly, G.J. and P. Licona, Epistemic Practices and Science Education, in History, Philosophy and Science Teaching. Science: Philosophy, History and Education, M. Matthews, Editor. 2018, Springer: Dordrecht. p. 139-165.

11. Roth, W.M. and L. Pozzer-Ardenghi, Pictures in Biology Education, in Multiple Representations in Biological Education, D.F. Treagust and C.-Y. Tsui, Editors. 2013, Springer Netherlands: Dordrecht. p. 39-53.

12. Sandoval, W.A. Designing Knowledge Representations for Learning Epistemic Practices of Science. in Annual Meeting of the American Educational Research Association. 2000. New Orleans.

13. Manzoni-de-Almeida, D., $O$ desenvolvimento da escrita argumentativa nas aulas de imunologia do ensino superior por metodologias ativas. Compartilhe Docência, 2016. 1(2): p. 3-19.

14. Manzoni-de-Almeida, D., P. Marzin-Janvier, and S.L.F. Trivelato, Analysis of epistemic practices in reports of higher education students groups in carrying out the inquiry-based activity of immunology. Investigações em Ensino de Ciências, 2016. 21(2): p. 105-120.

15. Toulmin, S.E., The Uses of Argument. 2003: Cambridge University Press.

16. Denzin, N.K. and Y.S. Lincoln, Introduction: The Discipline and Practice of Qualitative Research, in The Sage handbook of qualitative research, N.K. Denzin and Y.S. Lincoln, Editors. 2005, Sage Publications Ltd.: Thousand Oaks, CA. p. 1-32.

17. Mello, P.S., et al., Elaboração de uma atividade investigativa experimental em imunologia sobre o sistema do complemento para ensino superior: Relato da construção da sequência didática, in IV Congresso de Inovação e Metodologias do Ensino Superior (In Press). 2019: Belo Horizonte, M.G.

18. Jiménez-Aleixandre, M.P., A. Bugallo-Rodríguez, and R.A. Duschl, "Doing the lesson" or "doing science": Argument in high school genetics. Science Education, 2000. 84(6): p. 757792.

19. Kelly, G.J. and A. Takao, Epistemic levels in argument: An analysis of university oceanography students' use of evidence in writing. Science Education, 2002. 86(3): p. 314-342.

20. Goodwin, C., Professional Vision. American Anthropologist, 1994. 96(3): p. 606-633.

21. Jiménez-Aleixandre, M.P., Determinism and Underdetermination in Genetics: Implications for Students' Engagement in Argumentation and Epistemic Practices. Science \& Education, 2012. 23(2): p. 465-484. 


\section{List of captions}

Figure 1: Analysis of experimental questions, hypothesis and expected results produced in students' written material while submitted to protocol A.

Figure 2: Data representation by groups of students in protocol A. (A) Number of groups that performed non-verbal inscriptions. (B) Qualitative profile comparing the frequency of types of literary inscriptions in students' writings.

Figure 3: Appearances of each epistemic practice in the 15 written constructs from students submitted to protocol A.

Figure 4: Articulation of literary inscriptions. Estimated number of (A) constructs supported in data for each "Lab notebook"; and (B) literary inscriptions utilized, related to number of literary inscriptions performed in each "Lab notebook".

Figure 5: Analysis of experimental question, hypothesis and expected results produced in protocol B students' written material.

Figure 6: Data representation by groups of students subjected to protocol B. (A) Number of groups that performed non-verbal inscriptions. (B) Qualitative profile comparing the frequency of types of literary inscriptions in students' writings.

Figure 7: Appearances of each epistemic practices in 24 written constructs from students submitted to protocol B

Figure 8: Articulation of literary inscriptions. We estimated the number of (A) constructs supported in data for each "Lab notebook"; and (B) the number of literary inscriptions utilized that were related to the number of literary inscriptions performed in each "Lab notebook" 